\title{
RF MEMS Based Tunable Bowtie Shaped Substrate Integrated Waveguide Filter
}

\author{
Muhammad Zaka Ur REHMAN ${ }^{1,2}$, Zuhairi BAHARUDIN ${ }^{1}$, Mohd Azman ZAKARIYA ${ }^{1}$, \\ Mohd Haris Md. KHIR ${ }^{1}$, Muhammad Taha JILANI ${ }^{1}$ \\ ${ }^{1}$ Dept. of Electrical and Electronics Engineering, Universiti Teknologi Petronas, Tronoh, Perak, Malaysia \\ ${ }^{2}$ Dept. of Physics, COMSATS Institute of Information Technology, Park Road, Islamabad, Pakistan
}

zaka_g01951@utp.edu.my, zuhairb@petronas.com.my

\begin{abstract}
A tunable bandpass filter based on a technique that utilizes substrate integrated waveguide (SIW) and double coupling is presented. The SIW based bandpass filter is implemented using a bowtie shaped resonator structure. The bowtie shaped filter exhibits similar performance as found in rectangular and circular shaped SIW based bandpass filters. This concept reduces the circuit footprint of SIW; along with miniaturization high quality factor is maintained by the structure. The design methodology for single-pole triangular resonator structure is presented. Two different inter-resonator couplings of the resonators are incorporated in the design of the two-pole bowtie shaped SIW bandpass filter, and switching between the two couplings using a packaged RF MEMS switch delivers the tunable filter. A tuning of $1 \mathrm{GHz}$ is achieved for two frequency states of 6.3 and $7.3 \mathrm{GHz}$. The total size of the circuit is $70 \mathrm{~mm} \times 36 \mathrm{~mm} \times 0.787 \mathrm{~mm}$ ( L $\times W \times H)$.
\end{abstract}

\section{Keywords}

Substrate integrated waveguide (SIW), tunable filter, bowtie filter, RF MEMS, double coupling

\section{Introduction}

Filters have received a particular attention with the advent of various wireless systems, this interest has dramatically increased with the introduction and development of new millimeter waves applications over the past decade. Various applications have been recently proposed including wireless local area networks [1], radars [2], intelligent transportation systems [3] and imaging sensors [4]. Efficient filters demand has also increased with the development of chipsets operating at $60 \mathrm{GHz}$ or higher frequencies by a number of semiconductor industries [5].

Filters based on Substrate Integrated Waveguide (SIW) structures are achieved through incorporating the rectangular waveguide structure into the microstrip substrate [6]. SIWs are dielectric filled and are formed from the substrate material utilizing two rows of conducting vias connecting bottom and top metal plates, these vias are embedded in dielectric filled substrate; hence providing easy combination with other planar circuits and a reduction in size. The size reduction along with involving dielectric filled substrate instead of air-filled reduces the quality factor $(\mathrm{Q})$, but the entire circuitry including waveguide and microstrip transitions can be realized by using printed circuit board (PCB) technology or other techniques, like LCP [7] and LTCC [8].

The design of an SIW bandpass filter can either utilize a design methodology based on coupling matrix method [9], or it can also follow a methodology used for designing air filled waveguide filters. The design of an SIW filter based on the methodology adopted in a rectangular waveguide, a shunt inductive coupling realization is adopted. Vias of irregular diameters placed in the center of the cavity may possibly occur in an inductive post filter; which is based on a requirement of control couplings. Large couplings might occur in the use of a small diameter. The utilization of shunt inductive vias at the couplings of the filter realizes a shunt inductive coupling filter as depicted in Fig. 1 (a) or an iris (aperture) coupling post as shown in Fig. 1 (b). A detailed literature on the development of SIW filters has been reported in [10].

A three pole structure of a SIW bandpass filter based on shunt inductive vias is shown in Fig. 1 (a). It utilizes four coupling vias centered in the guide and two microstrip to SIW transitions at the input and output. The two vias at the transitions facilitate in input and output couplings, while the centered vias are for coupling between the resonators.

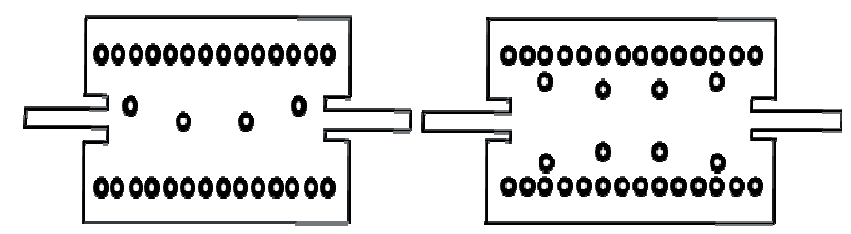

Fig. 1. (a) Shunt inductive coupling post filter. (b) Iris coupling based filter.

An SIW bandpass filter based on iris coupling posts is shown Fig. 1 (b); the apertures form three resonators. The 
filter's structure is such that the three cavities of half wavelength are formed in the center while SIW to microstrip transition are on the two edges of the filter; such a filter operational at $60 \mathrm{GHz}$ has been presented in [11].

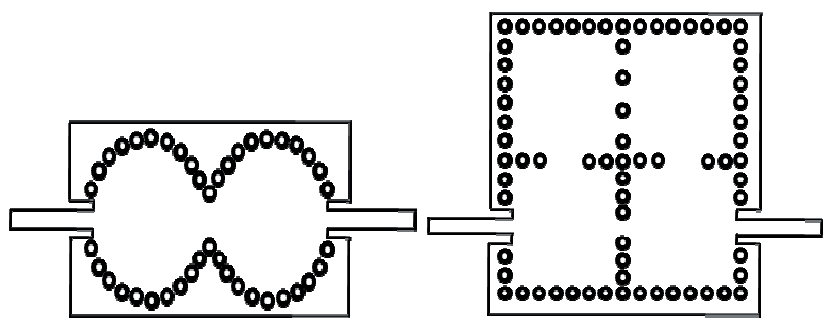

Fig. 2. Cavity filters with (a) circular cavities; (b) rectangular cavities.

Cavity filters with circular cavities[12] as presented in Fig. 2(a) and rectangular cavities [13] as depicted in Fig. 2(b) has been observed in literature. These variants of SIW allow more design variations and transmission zeros are also introduced due to cross coupling, better selectivity is also presented by these designs. Various SIW filters structures have been proposed in the literature; however there still exists a need to further miniaturize the structure. Furthermore the cavities are only either in circular or rectangular shape; therefore a triangular shaped cavity would reduce the circuit footprint.

In this paper, a tunable bandpass filter based on triangular cavity is presented. The tunable filter utilizes packaged RF MEMS switches which can be directly soldered on the filter circuit to switch the filter at two distinct frequencies. The tunable filter is designed through additional incorporation of a switchable extended coupling mechanism. As a validation of the proposed tunable filter, the design, fabrication and measured response of the two pole bowtie shaped bandpass filter are presented. The proposed bandpass filter configuration is suitable for integration with planar devices and its small footprint area allows other devices to be easily integrated on a single board.

\section{Triangular SIW Cavity Filter}

Design and implementation of SIW filters are being performed through defined practical methods so far. The most common technique is to form the SIW cavity through metallic sidewalls [14], a resemblance of which is displayed in Fig. 3. A dielectric substrate having thickness of $H$ forms the cavity and it is of length $L$ and width $W$. The bottom and top of the cavity are constructed through placing metallic plates and conducting posts/vias going through the substrate connecting the top and bottom plates; hence forming the sidewalls of the cavity. The vias are of diameter $d$ and the separation between two neighboring vias is given as $s$. The choice of diameter and separation between the two vias forms the basis of the SIW filters; therefore these should be selected in a manner that minimum radiation loss is exhibited.

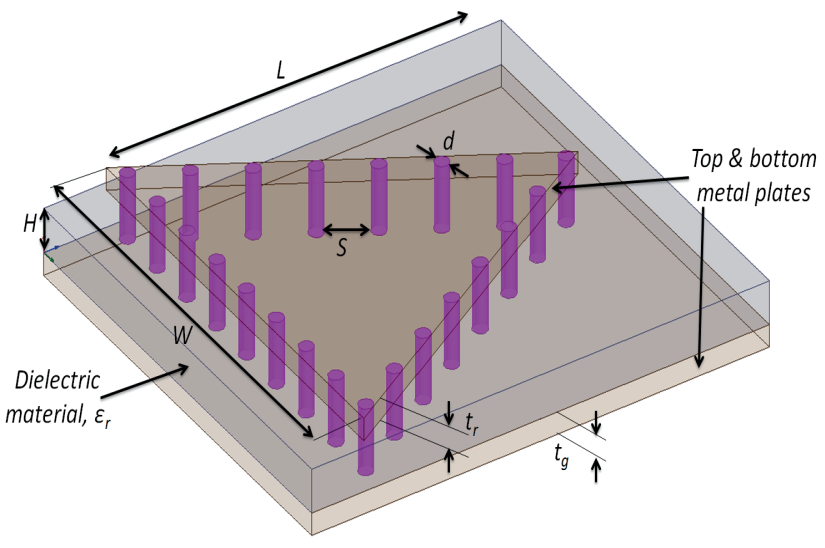

Fig. 3. Substrate Integrated Waveguide structure geometry.

The Deslandes and $\mathrm{Wu}$ [14] study reveals two primary design rules for SIW structures as given in (1) and (2); these rules are followed in order to ensure the same design and modeling methodology adopted for rectangular waveguides. These rules pertain to the diameter $d$ of the via posts and the via post spacing $s$ :

$$
\begin{aligned}
& d<\frac{\lambda_{g}}{5}, \\
& s \leq 4 d
\end{aligned}
$$

where $\lambda_{g}$ is the guided wavelength. In the design $d$ and $s$ are chosen to be $0.8 \mathrm{~mm}$ and $2 \mathrm{~mm}$ respectively, these values ensure less radiation losses and the SIW cavity acts closely to a triangular waveguide. For the $\mathrm{TE}_{101}$ mode, the dimensions of the SIW resonator structure are calculated by using the relation in (3) [14]

$$
f_{T E_{101}}=\frac{c}{2 \sqrt{\mu_{r} \varepsilon_{r}}} \sqrt{\left(\frac{1}{W_{e f f}}\right)^{2}+\left(\frac{1}{L_{e f f}}\right)^{2}} .
$$

$W_{\text {eff }}$ and $L_{\text {eff }}$ denote the effective width and length of the SIW resonator, respectively, and are given as:

$$
W_{\text {eff }}=W-\frac{d^{2}}{0.95 s}, \quad L_{e f f}=L-\frac{d^{2}}{0.95 s}
$$

where $W$ and $L$ are the real width and length of the SIW resonator, $\mu_{r}$ and $\varepsilon_{r}$ are the relative permeability and permittivity of the substrate respectively, and $c$ is the velocity of light in free space. In this design the width and length of the triangular resonator structure is computed using (3) and (4) as displayed in Fig. 3. Utilizing this method the cavity is designed for the specifications laid out in Tab. 1.

\begin{tabular}{|l|c|}
\hline Parameter & Value \\
\hline Tunable center frequency & $7.3 \mathrm{GHz}$ \\
\hline Chebyshev response filter order & 2 \\
\hline Passband ripples (dB) & 0.01 \\
\hline Passband bandwidth at $-3 \mathrm{~dB}$ & $>300 \mathrm{MHz}$ \\
\hline
\end{tabular}

Tab. 1. Design specifications of the tunable bandpass filter.

The printed circuit of triangular resonator and its subsequent bowtie shaped two pole filter is etched over 
using Rogers RT/Duriod 5880 material substrate having dielectric constant $\varepsilon_{\mathrm{r}}=2.2$ and substrate height $H$ of $787 \mu \mathrm{m}$, and a dissipation factor of $\tan \delta=9 \times 10^{-4}$. The copper thickness denoted as $t_{r}$ and $t_{g}$ is $17.5 \mu \mathrm{m}$.

The proposed triangular SIW cavity filter's resonance frequency is mainly dependent upon the dimensions of the cavity and the arrangement of vias forming the cavity walls. Theoretically, the resonance frequency does not depend on the thickness of the substrate $H$. However, it has been observed in literature [15] that it does play a role on the loss (mainly on radiation loss). The thicker the substrate the lower is the loss or higher is the Quality factor. Therefore, keeping in view the fabrication limitations a relatively thicker substrate is utilized for the SIW cavity.

\subsection{Single Inter-resonator and I/O Coupling}

In order to accomplish two pole bandpass SIW filter, once the triangular resonator is created for a specific resonant mode, the design methodology closely resembles conventional simulation-based microstrip filter design [14]. Two single resonators are coupled through inter-resonator coupling dimensions. In this coupling, a resonator length and coupling openings in both the resonators are used to couple the two resonators.

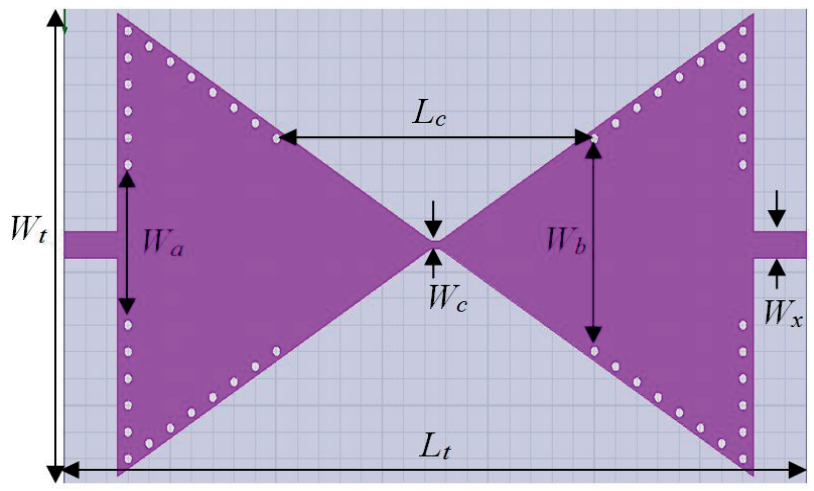

Fig. 4. Bowtie shaped two pole bandpass filter dimensions.

In Fig. 4 the dimensions are labeled and the values are given in Tab. 2, while the fabricated two pole bandpass filter with single coupling is depicted in Fig. 7.

External quality factor and coupling coefficients are calculated from derived expressions based on lowpass prototype parameters [14].

$$
K_{1,2}=\frac{F B W}{\sqrt{g_{1} g_{2}}}, \quad Q_{e 1}=\frac{g_{0} g_{1}}{F B W}, \quad Q_{e 2}=\frac{g_{2} g_{3}}{F B W}
$$

where $F B W$ is the fractional bandwidth, and $g_{0}, g_{1}, g_{2}, g_{3}$ are the Chebyshev lowpass prototype values which are used to calculate the external quality factors $Q_{\mathrm{e} 1}$ and $Q_{\mathrm{e} 2}$. The coupling coefficient $K_{1,2}$ computed based on second order Chebyshev response prototype parameters is compared with the simulated coupling coefficient obtained through weak coupling. The coupling coefficient's value is dependent of two parameters; the coupling opening width denoted as $W_{b}$ and inter-resonator combining width denoted as $W_{c}$. For $0.01 \mathrm{~dB}$ passband ripple, (5) results in values of $K_{1,2}=0.1402$ and $Q_{e 1}=Q_{e 2}=7.48$, then widths of $W_{c}$ and $W_{b}$ are selected from a closely matched coupling coefficients values. The values obtained through various combinations of the dimensions are depicted in Fig. 5.

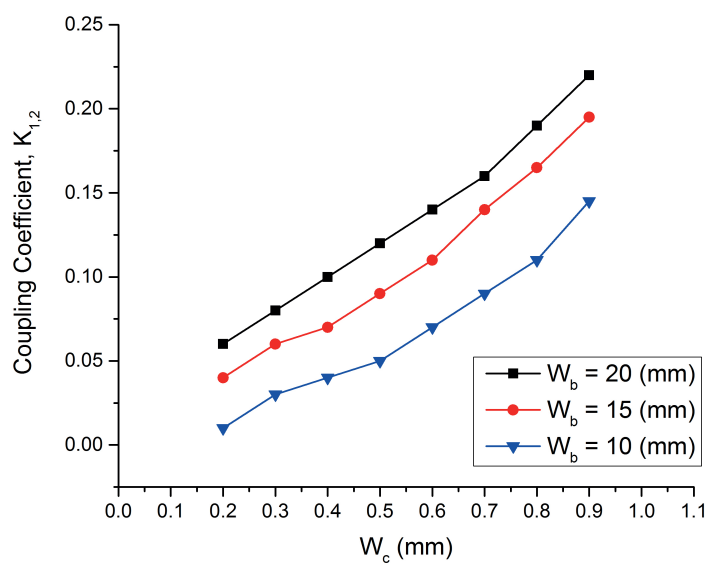

Fig. 5. Variation of inter-resonator dimensions against coupling coefficient

The microstrip to SIW transitions at the input and output ports are of width $W_{x}$, the dimensions of the feed lines are computed through transmission line calculator. However the input and output coupling openings denoted as $W_{a}$ are selected as a result of comparison of the simulated extracted external quality factors computed through (6) and external quality factors calculated on basis of theoretical LPF prototype parameters as given in (5)

$$
Q_{\text {ext }}=\frac{f_{0}}{\Delta f_{-3 d B}} .
$$

A selection of dimension resulting in a close match of theoretical and simulated external quality factors dictates the $\mathrm{I} / \mathrm{O}$ coupling as depicted in Fig. 6.

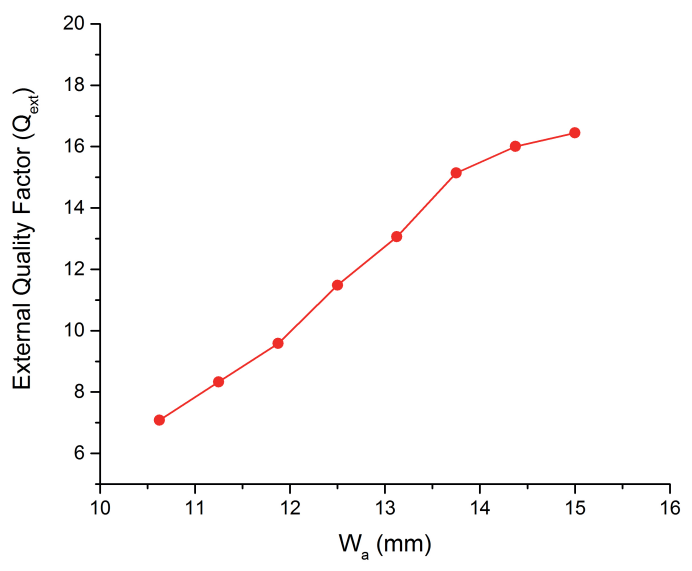

Fig. 6. External Q-factor for input/output coupling dimension.

The coupling is a result of iterations and adjustments to the dimensions of the coupling areas of the filter through full-wave simulations until desired filter and response is achieved. 


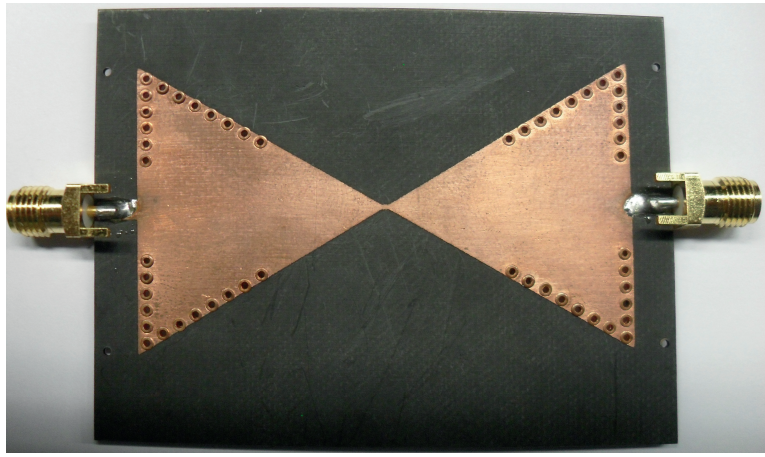

Fig. 7. Fabricated two pole fixed bandpass filter.

\subsection{Double Coupling and Tunable Structure}

An extended coupling overlaying the single coupling builds the basis of frequency shifting. The switching between the extended coupling and the single coupling forms tunable bandpass filter mechanism. The extended coupling is placed on top and bottom of the single coupling along with vias placed in the center of each length. The overlaying double coupling is shown in Fig. 8(a), while the notation values are displayed in Tab. 2 .

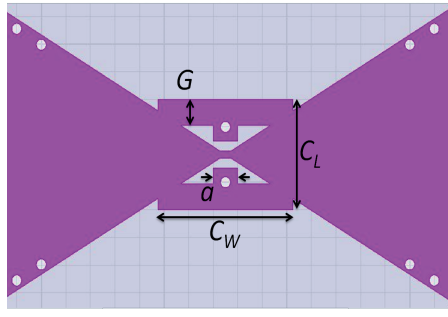

(a)

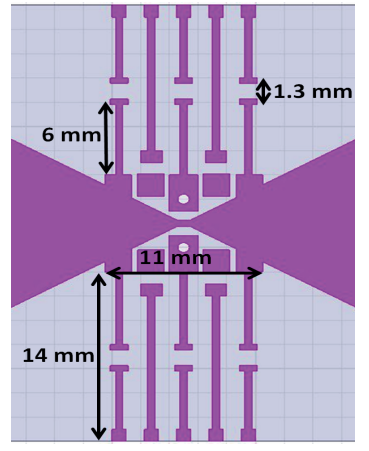

(b)
Fig. 8. (a) Overlaying double coupling, (b) Dimensions of bias circuitry.

\begin{tabular}{|c|c|c|c|}
\hline Notation & Value (mm) & Notation & Value (mm) \\
\hline$W_{t}$ & 36.0 & $W_{c}$ & 0.5 \\
\hline$L_{t}$ & 70.0 & $W_{x}$ & 2.0 \\
\hline$L$ & 35.0 & $L_{c}$ & 30.0 \\
\hline$W$ & 30.0 & $C_{w}$ & 11 \\
\hline$W_{a}$ & 12.0 & $C_{L}$ & 8 \\
\hline$W_{b}$ & 15.9 & $G, a$ & 2 \\
\hline
\end{tabular}

Tab. 2. Tunable filter parameters dimensions.

The tunable filter is constructed based on packaged RF MEMS switches, a total of four packaged RMSW201 RADANT MEMS [16]. The filters are actuated with a voltage of $90 \mathrm{~V}$, and an onboard bias circuitry is built to place the switches. The bias lines of $0.5 \mathrm{~mm}$ thickness with spacing of $1.5 \mathrm{~mm}$ are placed on the board to actuate the RF MEMS switches, the bias circuitry and its corresponding dimensions are shown in Fig. 8(b).

Fig. 9 shows the operational diagram of the RF MEMS switches along with its bias circuitry, a voltage of
$90 \mathrm{~V}$ is applied at the gate of the switch, while GND is connected through $100 \mathrm{k} \Omega$ resistors to the drain and source of the switch. The switches are placed on pads created on top of the board in between the coupling area, an on state of the switch refers to forming the double coupling whereas the off state refers to single coupling. The pads are wire-bonded to the gate, drain and source of the RF MEMS switches.

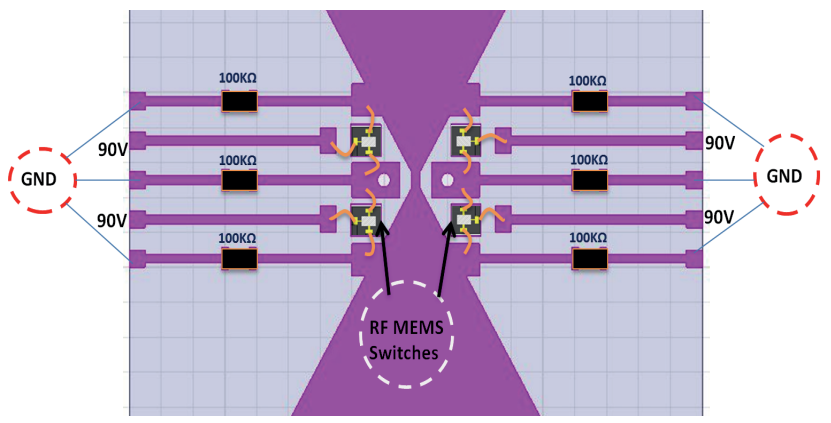

Fig. 9. The functionality and placement of RF MEMS and bias resistors (the figure is rotated).

\section{Results and Discussion}

The simulations to obtain the filter responses from the designed structures are conducted using ANSYS High Frequency Structure Simulator (HFSS). In addition Agilent Vector Network Analyzer (VNA) is utilized for the measurements of the fabricated filters.

The fixed filter described in the specifications in Tab. 1 and its corresponding design structure shown in Fig. 4 is realized with the responses shown in Fig. 10. The simulated $S_{21}$ and $S_{11}$ response of the bowtie shaped bandpass filter reveals that the $S_{11}$ value at the center frequency of $7.3 \mathrm{GHz}$ is less than $-30 \mathrm{~dB}$, whereas the $\mathrm{S}_{21}$ response is greater than $-0.5 \mathrm{~dB}$ and the passband bandwidth at $-3 \mathrm{~dB}$ is greater than $400 \mathrm{MHz}$. The measured $\mathrm{S}_{21}$ response at the center frequency of $7.3 \mathrm{GHz}$ is better than $-1.7 \mathrm{~dB}$ and its corresponding $S_{11}$ response at the center frequency is less than $-20 \mathrm{~dB}$. The passband bandwidth at $-3 \mathrm{~dB}$ is greater than $350 \mathrm{MHz}$.

The desired tunable filter with the double coupling shown in Fig. 8 and Fig. 9 is realized with the responses shown in Fig. 11 and Fig. 12. The details of the passband are depicted in Fig. 11(a) and Fig. 12(a) for the simulated and measured $\mathrm{S}_{21}$ responses, respectively.

Fig. 11 shows the response of the simulated two pole tunable filter designed for two resonant frequencies of 6.3 and $7.3 \mathrm{GHz}$. Response of the filter is obtained through realizing the resonator structure designed using the equations presented in Sec. 2.

The simulated $\mathrm{S}_{21}$ and $\mathrm{S}_{11}$ response of the bowtie shaped tunable bandpass filter reveals that when the switch is disconnected a two pole bandpass response is achieved at $6.3 \mathrm{GHz}$, whereas when the RF MEMS switch connects 


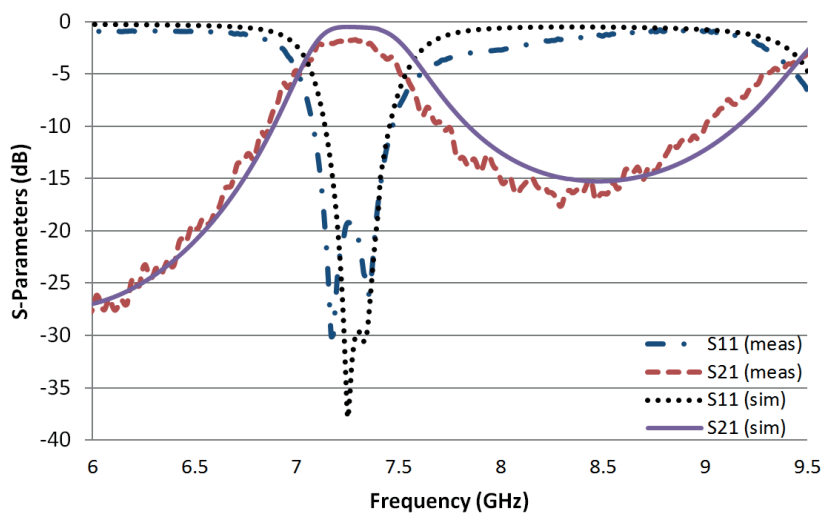

Fig. 10. Response of the fixed bowtie bandpass filter.

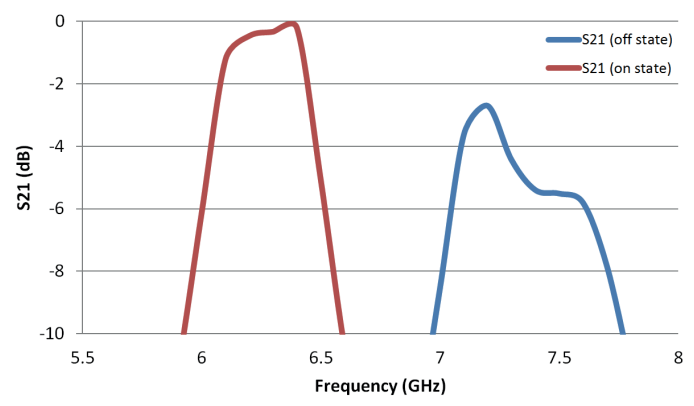

Fig. 11. (a) Passband details for the simulated $S_{21}$ response.

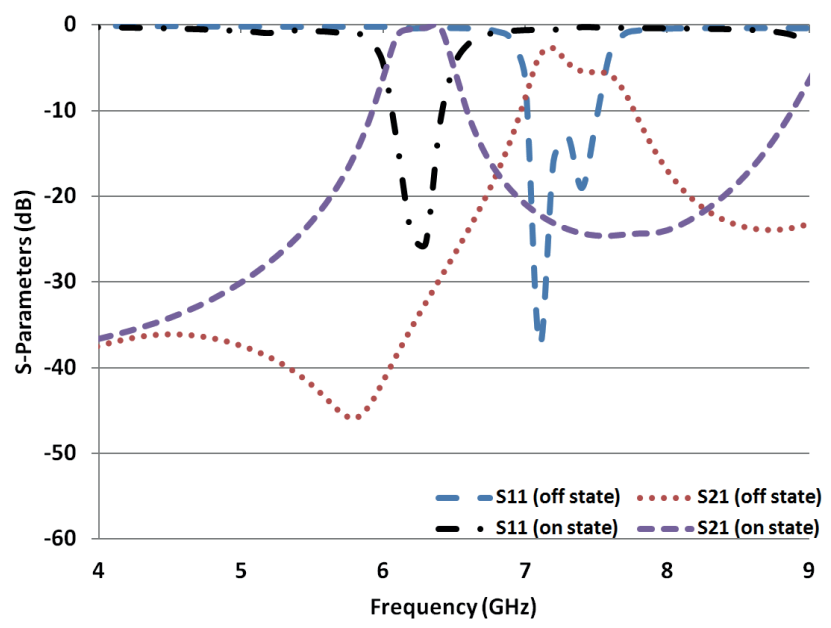

Fig. 11. (b) Simulated response of the tunable bandpass filter.

the double layered coupling a resonant frequency of $7.3 \mathrm{GHz}$ is achieved. The passband bandwidth at $-3 \mathrm{~dB}$ for both the resonant frequencies is observed to be greater than $400 \mathrm{MHz}$.

Measured $\mathrm{S}_{21}$ and $\mathrm{S}_{11}$ response of the two pole bandpass filter is presented in Fig. 12. The measured responses show similar trends in terms of frequency tuning between the two resonant modes as observed in the simulated responses. The $\mathrm{S}_{21}$ responses at the center frequencies of 6.44 and $7.4 \mathrm{GHz}$ are better than $-7 \mathrm{~dB}$ and their corresponding $\mathrm{S}_{11}$ responses are less than $-14 \mathrm{~dB}$ and $-18 \mathrm{~dB}$ respectively. The passband bandwidth at $-3 \mathrm{~dB}$ is greater than $400 \mathrm{MHz}$, whereas the lower and upper stopband rejections are better than $-25 \mathrm{~dB}$. These responses are summarized in Tab. 3.

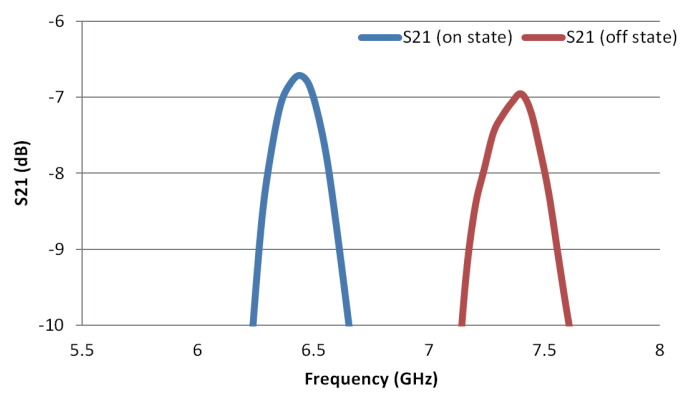

Fig. 12. (a) Passband details for the measured $S_{21}$ response.

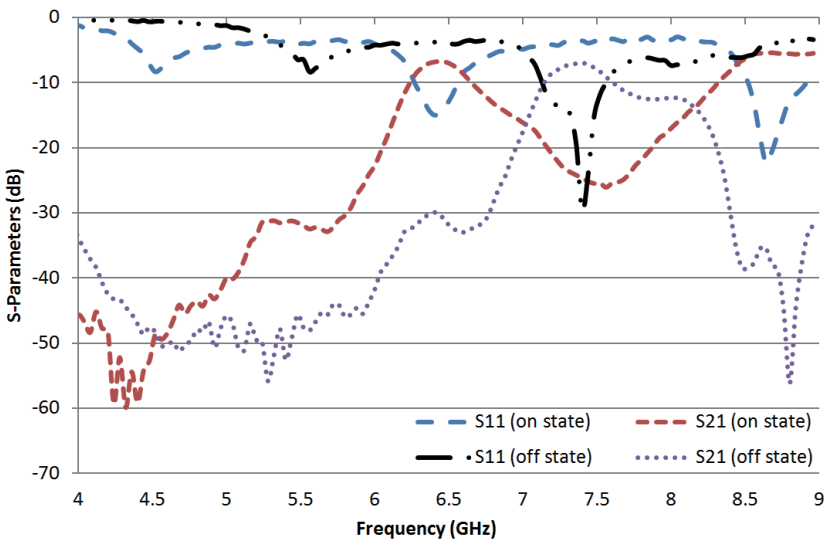

Fig. 12. (b) Measured response of the two pole tunable filter.

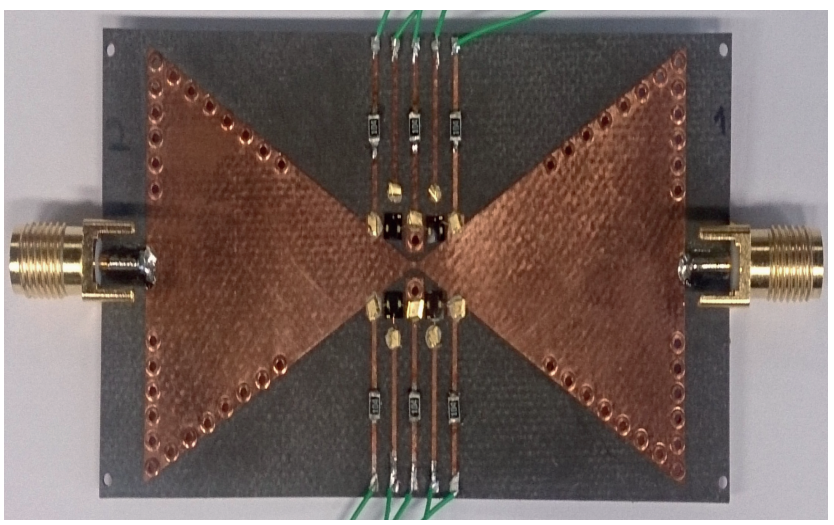

Fig. 13. Fabricated bowtie shaped tunable two pole filter.

\begin{tabular}{|l|c|c|}
\hline Key Parameters & Simulated & Measured \\
\hline Passband center frequency $(\mathrm{GHz})$ & $6.3,7.3$ & $6.44,7.4$ \\
\hline Passband $\mathrm{S}_{11}(\mathrm{~dB})$ & $<25,20$ & $<14,18$ \\
\hline Passband $\mathrm{S}_{21}(\mathrm{~dB})$ & $>-0.5,-3.5$ & $>-7,-7.5$ \\
\hline Stopband rejection $(\mathrm{dB})$ & $>25$ & $>25$ \\
\hline Passband bandwidth at $-3 \mathrm{~dB}$ level & $0.4 \mathrm{GHz}$ & $0.435 \mathrm{GHz}$ \\
\hline
\end{tabular}

Tab. 3. Summary of the tunable bandpass filter performance.

The measured insertion loss response includes the losses of the SMA connectors at the input and output of the tunable bandpass filter. The upper passband produced due to cancellation of the $\mathrm{TE}_{101}$ and $\mathrm{TE}_{201}$ modes is distanced enough from the filter passband, hence a pure Chebyshev response is observed as the design was based on Chebyshev LPF prototype parameters. However high order resonant modes presents spurious at $10 \mathrm{GHz}$. Consequently suppression of spurious is achievable by employing low- 
pass filters at the input and output of the resonators. Therefore the cut-off for the lowpass filters has to be matched with the upper passband of the bandpass filter.

\section{Conclusion}

A tunable bowtie shaped bandpass filter based on RF MEMS switches utilizing triangular structure SIW is proposed in this paper, the filter exhibits good performance and a miniaturized version of the SIW structure is exploited in the design process. The tunable filter is unique in terms of the tuning mechanism exploiting the coupling area. The RF MEMS two states switchable bandpass filter is designed, simulated, fabricated and the measured filter response shows two distinct frequency states at 6.4 and $7.4 \mathrm{GHz}$ with a nearly constant bandwidth of $400 \mathrm{MHz}$. The simple structure of the filter allows readily integration with planar circuits and devices.

\section{Acknowledgements}

This work was supported by the Fundamental Research Grant Scheme (FRGS) of the Department of Higher Education, Malaysia. The authors would like to thank Dr. John Ojur Dennis and his student Mr. Farooq Ahmed of Nano fabrication facility in Universiti Teknologi PETRONAS, Malaysia for providing their guidance and wirebonding facility.

\section{References}

[1] JAMES, J., PENGBO SHEN, NKANSAH, A., XING LIANG, GOMES, N. J. Millimeter-wave wireless local area network over multimode fiber system demonstration. IEEE Photonics Technology Letters, 2010, vol. 22, no. 9, p. 601-603. DOI: 10.1109/LPT.2010.2043249

[2] LI WANG, GLISIC, S., BORNGRAEBER, J., WINKLER, W., SCHEYTT, J. C. A single-ended fully integrated $\mathrm{SiGe} 77 / 79 \mathrm{GHz}$ receiver for automotive radar. IEEE Journal of Solid-State Circuits, 2008, vol. 43, no. 9, p. 1897-1908. DOI: 10.1109/JSSC.2008.2003994

[3] YAN, X., ZHANG, H., WU, C. Research and development of intelligent transportation systems. In Proceedings of the $11^{\text {th }}$ International Symposium on Distributed Computing and Applications to Business Engineering \& Science. Guilin (China), 2012, p. 321-327.

[4] Wilson, J. P., SCHUETZ, C. A., MARTIN, R., Dillon, T. E., YAO, P., PRATHER, D. W. Polarization sensitive millimeterwave imaging sensor based on optical up-conversion scaled to a distributed aperture. In Proceedings of the 37th International conference on Infrared, Millimeter, and Terahertz Waves. Wollongong (Australia), 2012, vol. 1, p. 23-28.

[5] NIKNEJAD, A. M., HASHEMI, H. Millimetre-wave Silicon Technology: $60 \mathrm{GHz}$ and beyond. Springer, 2008.

[6] HIROKAWA, J., ANDO, M. Single-layer feed waveguide consisting of posts for plane TEM wave excitation in parallel plates. IEEE Transactions on Antennas and Propagation, 1998, vol. 46, no. 5, p. 625-630. DOI: 10.1109/8.668903

[7] KI SEOK YANG, PINEL, S., IL KWON KIM, LASKAR, J. Lowloss integrated-waveguide passive circuits using liquid-crystal polymer System-on-Package (SOP) technology for millimeterwave applications. IEEE Transactions on Microwave Theory and Techniques, 2006, vol. 54, no. 12, p. 4572-4579. DOI: 10.1109/TMTT.2006.886004

[8] JUNFENG XU, ZHI NING CHEN, XIANMING QING, WEI HONG. 140-GHz planar broadband LTCC SIW slot antenna array. IEEE Transactions on Antennas and Propagation, 2012, vol. 60, no. 6, p. 3025-3028. DOI: 10.1109/TAP.2012.2194673

[9] MOKHTAARI, M., BORNEMANN, J., RAMBABU, K., AMARI, S. Coupling-matrix design of dual and triple passband filters. IEEE Transactions on Microwave Theory and Techniques, 2006, vol. 54, no. 11, p. 3940-3946. DOI: 10.1109/TMTT.2006.884687

[10] REHMAN, M. Z. U., BAHARUDIN, Z., ZAKARIYA, M., KHIR, M., KHAN, M., WENG, P. W. Recent advances in miniaturization of substrate integrated waveguide bandpass filters and its applications in tunable filters. In Proceedings of Business Engineering and Industrial Applications Colloquium. (Malaysia), 2013, p. 109-114. DOI: 10.1109/BEIAC.2013.6560093

[11] SUNG TAE CHOI, KI SEOK YANG, TOKUDA, K., YONG HOON KIM. A V-band planar narrow bandpass filter using a new type integrated waveguide transition. IEEE Microwave and Wireless Components Letters, 2004, vol. 14, no. 12, p. 545-547. DOI: 10.1109/LMWC.2004.837386

[12] TANG, H. J., HONG, W., HAO, Z. C., CHEN, J. X., WU, K. Optimal design of compact millimetre-wave SIW circular cavity filters. Electronics Letters, 2006, vol. 41, no. 19, p. 1068-1069. DOI: $10.1049 / \mathrm{el}: 20052251$

[13] XIAO-PING CHEN, KE WU. Substrate integrated waveguide cross-coupled filter with negative coupling structure. IEEE Transactions on Microwave Theory and Techniques, 2008, vol. 56, no. 1, p. 142-149. DOI: 10.1109/TMTT.2007.912222

[14] DESLANDES, D., WU, K. Accurate modeling, wave mechanisms, and design considerations of a substrate integrated waveguide. IEEE Transactions on Microwave Theory and Techniques, 2006, vol. 54, no. 6, p. 2516-2526. DOI: 10.1109/TMTT.2006.875807

[15] ALI KHAN, A., MANDAL, M. K., SANYAL, S. Unloaded quality factor of a substrate integrated waveguide resonator and its variation with the substrate parameters. In Proceedings of International Conference on Microwave and Photonics. Dhanbad (India), 2013, p. 1-4. DOI: 10.1109/ICMAP.2013.6733496

[16] RADANT MEMS, MA, USA. RMSW201 SPST RF MEMS switch (datasheet). 2 pages. [Online] Cited 2014-05-10. Available at: http://www.radantmems.com/radantmems.data/Library/RMSW201. pdf

\section{About the Authors ...}

Muhammad Zaka Ur REHMAN was born in Lahore, Pakistan in 1986. He is serving as a Lecturer in COMSATS Inst. of Information Technology (CIIT), Islamabad, Pakistan. He received his B.S. degree in Electronics from CIIT in 2007, the MSc Degree in Digital Signal Processing in Communication Systems from Lancaster University, UK, in 2010, and is currently working towards the Ph.D. degree in Electrical Engineering (with an emphasis on RF and Microwave Circuits) at the Universiti Teknologi PETRONAS, Perak, Malaysia. His research interests include RF MEMS for microwave applications, substrate integrated waveguide structures and reconfigurable filters design. 
Zuhairi BAHARUDIN is a faculty member at Universiti Teknologi PETRONAS, Malaysia. He obtained his Diploma and B.Eng. Hons. Electrical from the University Technology MARA, Shah Alam, Malaysia and subsequently his M.Eng in Electrical Power Engineering from the University of South Australia, Australia. He received his Ph.D. degree in Electrical Engineering from the Universiti Teknologi PETRONAS in 2010. His research interests are in effects of harmonics on power systems, applications of artificial intelligence of load forecasting, and power economics operation and control.

Mohd Azman Bin ZAKARIYA received bachelors in Electrical Engineering from Universiti Teknologi Malaysia, and Master of Science in Communications and Signal Processing from University of Newcastle upon Tyne, UK. $\mathrm{He}$ is a lecturer in Universiti Teknologi PETRONAS, Malaysia. He is also working towards his Ph.D. from Universiti Sains Malaysia. His research interests include dielectric resonator antennas, defected ground structure.

Mohd Haris Md KHIR received the B. Eng. degree in Electrical and Electronic Engineering from Universiti Tek- nologi MARA, Selangor, Malaysia, in 1999, the Masters of Science degree in Computer \& System Engineering from Rensselaer Polytechnic Institute, New York, USA, in 2001, and the Ph.D. degree in Systems Engineering from Oakland University, Michigan, USA, in 2010. Since 2002, he has been with Universiti Teknologi PETRONAS, Perak, Malaysia, where he is currently a Senior Lecturer in Electrical \& Electronic Engineering Department. His research interests include Micro-Electro-Mechanical Systems (MEMS) sensors/actuators design and fabrication based on CMOS and MUMPS technologies. He has successfully fabricated a number of MEMS devices such as accelerometers, micro-mirror, micro switches, energy harvester, electromagnetic sensors, gas sensors, and thermal electric generator (TEG) system.

Muhammad Taha JILANI received bachelor's degree in Electrical Technology followed by masters in Telecommunication, in 2007 \& 2009 respectively. He is currently working toward Ph.D. in the area of dielectric material characterization using RF and microwave frequencies at Universiti Teknologi PETRONAS, Malaysia. 